\title{
Verbond en sosiale prediking - Sosiale aspekte in die teologie van Deuteronomium
}

M H O Kloppers

\begin{abstract}
Covenant and social preaching - Social aspects in the theology of Deuteronomy

Deuteronomy is generally viewed as a book containing clear covenant elements. The question posed in this article is to what extent social preaching is connected with covenant preaching within the scope of the theology of Deuteronomy. To answer this question a series of pericopes dealing with matters like slavery, poverty and other ethical and social aspects is scrutenized. Some results are offered giving quite positive answers to the question.
\end{abstract}

Deuteronomium word breedweg aanvaar as 'n Bybelboek met verbondselemente daarin' ${ }^{1}$. Sommige navorsers wil dit selfs as 'n blote verbondsdokument hanteer' Om dit as ' $n$ "dokument" te hanteer laat egter nie die karakter van die boek tot sy reg kom nie en misken veral die sterk paranetiese aard daarvan. Daarom moet daar met beide elemente as vertrekpunte gewerk word wanneer Deuteronomium nagevors word: sowel die predikende aard as die sterk onderliggende verbondskarakter daarvan. Die siening dat Deuteronomium verbondsprediking is met die verbondswet en die verbondsvolk as "teks" sou daarom 'n goeie vertrekpunt wees. Die vraag wat hier aan die orde kom, is in hoeverre "sosiale prediking" in dié boek 'n plek kry en selfs 'n noodsaaklike funksie vervul' ${ }^{3}$. Hoe funksioneer "sosiale prediking" binne die verbondsprediking, en kan verbondsprediking daarsonder tot sy reg kom? Die antwoorde op hierdie vrae moet in die teologie van Deuteronomium gesoek word.

Met die oog daarop word aanvanklik 'n seleksie van perikope ondersoek om daarna sekere gevolgtrekkings te maak ${ }^{4}$. In die geselekteerde perikope word eers gekyk na die hantering van slawerny. Daarna kom die groep wat as minderbevoorregtes getipeer kan word, naamlik die armes, die weduwees, die weeskinders en die vreemdelinge aan die orde. Aspekte soos vryskelding, skuldkwytskelding, ensomeer, word terselfdertyd ondersoek. Uiteindelik word ondersoek ingestel na aspekte wat saamhang met oorlogsetiek, sosiale probleme en die hantering van misdade en oortreders. 
Hieronder word sowel na die verskynsel self as na die hantering van slawe in die algemeen gekyk .

Die belangrikste perikoop in verband met slawerny, is Deuteronomium 15:12-18, terwyl algemene verwysings na slawe/slavinne (of die dienskneg en diensmaagd) of slawerny voorkom in $5: 6,14,15,21 ; 6: 12,21 ; 7: 8 ; 8: 14 ; 12: 12,18$; $13: 5,10 ; 15: 15-18 ; 16: 11,12,14 ; 21: 14 ; 23: 15,16 ; 24: 7,18,22 ; 28: 68$. Hier word die aandag toegespits op 15:12-18, daarna op 23:15-16 en uiteindelik 12:12,18;16:11,14. Die ander teksverwysings dien as algemene motiverings en veral motiverings ten opsigte van groepe minderbevoorregtes wat mettertyd aandag sal ontvang.

$1.1 \quad$ Deuteronomium 15:12-18

A 12 'n Persoon wat as slaaf "verkoop" is aan 'n volksgenoot moet na ses jaar diens as vryman kan weggaan.

B 13-14 Die reëling van die manier waarop hy weggaan: nie met leë hande nie. 'n Behoorlike voorraad van alles moet aan hom geskenk word.

C 15 Die motivering is geleë in die feit dat Israel self eers slawe in Egipte was, maar deur die Here daaruit verlos is.

B 16-17 Die reëling van 'n seremonie ingeval 'n slaaf of slavin verkies om nie weg te gaari nie.

A 18 Die vrylating van 'n slaaf as vryman mag nie vir 'n volksgenoot 'n moeilike saak wees nie, en die seën van die Here word hierin beloof.

1.1.1 Die oorkoepelende gedagte word in verse 12 en $18(\mathrm{~A}+\mathrm{A})$ gevind waarin die opdrag gegee word om die slaaf na ses jaar diens as "vryman" te laat weggaan en dit met 'n goeie gesindheid.

1.1.2 Die beginsel van vryskelding van slawe is hier die onderliggende motief, en dit is terselfdertyd ' $n$ belangrike voorskrif vir die hantering van slawe in die algemeen. 
1.1.3 Twee basiese reëlings word getref in verse 13-14 en weer 16-17 $(B+B)$, naamlik die voorsiening van 'n goeie voorraad aan die slaaf wat weggaan, en aan die ander kant, die seremonie vir'n slaaf wat nie wil weggaan nie.

1.1.4 Die motivering staan in die sentrum, naamlik in vers 15 (C). Dit gaan egter nie net om humanitêre of ander sosiale redes nie. Die diepste begronding lê in die verbondsverhouding met die Here wat sy volk uit slawerny bevry het. Uit dankbaarheid teenoor Hom en as 'n getuienis van Hom moet hierdie daad verrig word. Hierdie motivering kom algemeen in Deuteronomium voor ( $\mathrm{vgl}$ o a $6: 21 ; 7: 8$; $8: 14$ ), maar word ook spesifiek in verband met die gesindheid teenoor minderbevoorregtes of slawe gebruik (vgl o a 5:15; 24:18,22). Trouens, die motivering van die vierde gebod in Deuteronomium 5:15 bepaal nie net die betekenis van hierdie gebod nie, maar staan ook in verband met die hantering van die dienskneg en diensmaagd.

\subsection{Deuteronomium 23:15-16}

Hier is 'n reëling in verband met die behandeling van 'n slaaf wat van sy eienaar weggeloop het en by 'n Israeliet tereg kom.
A 15
So 'n slaaf mag nie aan sy eienaar uitgelewer word nie.
B 16
Aan so 'n slaaf moet die nodige verblyf en beskerming verleen word.

Hierdie reêling het sowel 'n negatiewe (A) as 'n positiewe (B) element. Dit gaan oor die goeie versorging van so 'n slaaf. Alhoewel daar nie 'n motivering daarvoor gegee word nie, kan aangeneem word dat dit in lyn lê met die waarheid dat Israel slawe was en daaruit verlos is (vgl v 13-14).

\subsection{Deuteronomium 12:12 (vgl ook 12:18; 16:11,12,14)}

In hierdie perikoop handel dit oor die voorskrif dat die volk hulle offers na die plek wat die Here sal uitkies, moet bring en daar met blydskap voor die Here verkeer. Die volgende lys van persone wat hierin moet deel, word dan pertinent genoem: seuns en dogters, slawe en slavinne, die Leviet.

Die volgende aantekeninge is hier van belang:

Sowel in 12:18 waar dit gaan oor die offers en tiendes, as in 16:11,14 waar dit gaan 
oor die viering van die fees van die weke en die loofhuttefees, word dieselfde lys verskaf: seun en dogter, slaaf en slavin, die Leviet. In 16:11 en 14 word die vreemdeling, die weeskind en die weduwee bygevoeg. By die bepaling in 16:11 kom die motivering in 16:12 by dat hulle moet onthou dat hulle slawe was en dat die Here hulle daaruit verlos het. Die bedoeling is duidelik. Wanneer die bondsvolk voor die Here kom, hetsy in hulle offerandes of hulle feeste, moet die slaaf en slavin (saam met ander minderbevoorregtes) ook daarin deel. By die godsdienstige byeenkomste mag geen klasseverskil gehandhaaf word nie. Alhoewel die begronding net in 16:12 voorkom, kan aangeneem word dat dit as begronding vir al hierdie voorskrifte geld.

\section{DIE HANTERING VAN MINDERBEVOORREGTES}

Fyner onderskeidinge sou hier gemaak kon word, maar omdat die vreemdeling, die weeskind en die weduwee in Deuteronomium gewoonlik saam hanteer word as die minderbevoorregte groep, word dit hier ook op dié wyse gedoen. Die Leviet het geen grond besit nie en het geleef van die offergawes wat na die heiligdom toe gebring is 5 . Die Leviet word daarom dikwels saam met hierdie groep genoem en by hulle ingesluit. In enkele gevalle word die dienskneg en die diensmaagd ook saam met die groep hanteer en in 'n enkele geval ook die houthakker en die waterputter. Verwysings na sowel hierdie groepe as na armes in die algemeen kom voor in 1:16; $5: 15 ; 10: 18,19 ; 14: 21,27,29 ; 15: 4,7-11 ; 16: 11,14 ; 18: 6-8 ; 23: 7 ; 24: 14,17-21 ; 25: 7$; $26: 11,12,13,19 ; 29: 11$. Die volgende perikope word hier behandel: 10:12-11:1; 15:7$11 ; 24: 17-22 ; 26: 12-13$.

\subsection{Deuteronomium 10:12-11:1}

Dit is 'n belangrike perikoop wat sowel die praktiese reëlings as die basiese motivering ten opsigte van die hantering van minderbevoorregtes betref ${ }^{6}$.
A 12
Jy moet die Here liefhè, gehoorsaam en dien, en ook gehoorsaam wees aan sy gebooie en voorskrifte.
$\begin{array}{ll}\text { B } 14 & \text { Die hemel en aarde behoort aan die Here, } \\ 15 & \text { tog het Hy net sy liefde aan hulle voorvaders bewys. }\end{array}$
C 16
Wy jou aan die Here, wees nie hardkoppig nie.
D 17
Die Here is alleen God. Hy is groot, doen wonderdade, is nie partydig nie en neem nie omkoopgeld aan nie. 
Hy laat reg geskied aan weeskind en weduwee en het die vreemdeling lief.

D 19 Jy moet die vreemdelinge liefhê, want jy was ook een in Egipte.

C 20 Jy moet die Here eer, dien en aanhang en slegs in sy Naam 'n eed aflê.

B 21 Jy moet die Here prys, want hy is die Een wat die groot wonderdade doen.

22 Jou voorvaders was net sewentig toe hulle in Egipte gekom het, maar die Here het hulle so baie gemaak soos die sterre in die hemel.

A 1 Jy moet die Here liefhê en sy opdragte, voorskrifte, bepalings en gebooie gehoorsaam.

In die buiteraam $(\mathrm{A}+\mathrm{A})$ gaan dit basies om die opdrag om die Here lief te hê en te gehoorsaam, en dit word deur verskeie ander begrippe versterk. In die volgende omraming $(B+B)$ word die motivering vir hierdie eis gegee, deur die Here wat sy volk liefgekry, uitgekies en geseën het, se grootheid te beskryf. In die volgende omraming $(C+C)$ lê twee opdragte, naamlik om hulle aan die Here toe te wy en Hom in alle opsigte te eer. Hierbinne lê die kernstuk $(D+D)$ waarin dit gaan om die wyse waarop hierdie liefde gestalte moet kry, naamlik in die korrekte verhouding tot die weeskind, die weduwee en die vreemdeling. Hier moet die godsdienstige motivering weer raakgesien word, wat veral met die vreemdeling in verband gebring word. Die Here het die vreemdeling lief en daarom moet sy volk ook die vreemdeling liefhê, want hulle mag nooit vergeet dat hulle self vreemdelinge in Egipte was nie.

\subsection{Deuteronomium 15:7-11}
A $7-8$
Daar mag ' $n$ arm mede-Israeliet in een van hulle stede wees. Hulle mag egter nie suinig wees nie, maar aan hom leen wat hy nodig het.

B 9

Die naderende jaar van afskrywing (die sewende jaar) mag hulle nie ten opsigte hiervan verkeerd (sondig) laat optree nie. 
B 10 Hulle moet vrylik gee, want juis daarom gee die Here ook aan hulle ryklik.

A 11 Daar sal altyd armes wees en daarom die opdrag deur die Here dat hulle vrygewig moet wees.

In die buiteraam $(\mathrm{A}+\mathrm{A})$ word die feit van armoede bekendgestel as 'n verskynsel wat altyd sal voorkom en ten opsigte waarvan die Here die opdrag tot vrygewigheid gee. Die Here wil op hierdie wyse 'n bepaalde lewenshouding by hulle kweek.

In die binneraam $(B+B)$ word aan die een kant 'n moontlike negatiewe en sondige houding beskryf, naamlik dat hulle sodanige hulp sal weerhou omdat hulle dit in die komende jaar van kwytskelding kan verloor. Die positiewe element aan die ander kant beklemtoon die waarheid dat wie vrywillig gee ook sal ervaar dat die Here ryklik voorsien.

Hierdie voorskrif is 'n belangrike uitloper van die voorskrif oor skuldafskrywing wat aan die einde van elke sewe jaar moet geskied en wat breedvoerig beskryf word in 15:1-6 en Levitikus 25:1-7. In beide gevalle is barmhartigheid teenoor die arme die onderliggende motivering vir die voorskrif.

Hierdie voorskrif het 'n opvallende godsdienstige motivering. Om betrokke te bly by armoede, is deel van God se plan met sy verbondsvolk. In hulle houding daarteenoor moet iets van die Here se genadige bemoeienis met die mens weerspieël word.

\subsection{Deuteronomium 24:17-22}

B 17 Die regte van die vreemdeling, weeskind of weduwee mag nie geskend word nie en daarom mag die kledingstuk van 'n weduwee ook nie as pand geneem word nie.

C 18 Hulle moet onthou dat hulle slawe was in Egipte en dat die Here hulle uit daardie nood verlos het.

A 19a Wanneer die lande geoes word, mag 'n gerf wat vergeet word, nie weer gehaal word nie.

B 19b Dit is vir die vreemdeling, weduwee en weeskind.

A 20a Wanneer hulle klaar olywe afgeslaan het, mag hulle nie teruggaan om nog af te slaan nie.

B 20b Dit is vir die vreemdeling, weduwee en weeskind. 
A 21a Wanneer hulle die wingerde afgeoes het, mag hulle dit nie vir 'n tweede keer deurgaan vir 'n verdere oes nie.

B 21b Dit is vir die vreemdeling, weduwee en weeskind.

C 22 Hulle moet onthou dat hulle slawe was in Egipte en dat die Here hulle uit daardie nood verlos het.

Hierdie gedeelte gaan om 'n groep minderbevoorregtes, naamlik die vreemdeling, weduwee en weeskind wie se regte op geen wyse aangetas mag word (B; vgl Eks 2124; Lev 19:9-10), hetsy deur die ontneming van 'n kledingstuk (v 17), of die miskenning van bepaalde oesvoorskrifte nie (A): die gaan haal van die orige koring op die land ( $\mathrm{v} 19$ ), of die oes van die olywe wat aan die olyfbome agtergebly het ( $\mathrm{v}$ 20 ), of die pluk van nog druiwe aan die wingerstok (v 21). Dit was bepaalde regte wat ingebou is om die minderbevoorregtes te versorg (vgl Lev 19:9-10; Rut 2:2-18).

Weer eens is die begronding $(C)$ godsdienstig van aard. Hulle moet onthou dat hulle slawe was in Egipte en dat die Here hulle uit daardie nood verlos het.

2.4 Deuteronomium 26:12-13

A 12 Elke derde jaar is dit die jaar van die tiendes. Dan moet hierdie gawes na die Leviet, die vreemdeling, die weeskind en die weduwee gaan sodat hulle genoeg kan hè om te eet.

B 13 Dit moet gepaard gaan met 'n belydenis dat hulle hierdie groepe versorg het in opdrag van die Here.

Hier word daar op 'n positiewe wyse voorsiening gemaak vir die versorging van die behoeftiges (A). Só moes voorsien word in hulle voedselbehoeftes.

Hierdie lewenshouding is egter gegrond in die voorskrifte van die Here. Wie dit uitvoer, doen so die wil van die Here.

Dit hang verder saam met die belydenis van die persoon wat die voorsiening maak, dat hy dit doen as deel van die verbondsvolk wat die redding van die Here op 'n merkwaardige wyse ervaar het. 
Net enkele perikope word hier in behandeling geneem. In 19:15-21 word die belangrikste beginsels vir die hantering van misdade hanteer. In 20:1-20 en 21:10-14 word beginsels vir oorlogvoering neergelê. Bepaalde reëlings vir 'n ordelike gemeenskap waar "sosiale reg" moet geskied, kom in die volgende gedeeltes onder die soeklig: 19:1-14; 22:1-30 en 23:15-25. Die perikoop 19:1-14 word in sy geheel behandel. By 22:1-30 word net verse 1-5, 6-8, 13-21 hanteer aangesien die res op 'n ander vlak lê. By 23:15-25 word die aandag bepaal by verse 19-20 en 24-25 aangesien verse $15-16$ reeds behandel is (by 1.2), vers 17 oor prostitusie en verse 18,21-23 oor geloftes aan die Here handel.

\subsection{Deuteronomium 19:15-21}
A 15
Beskuldigings teen iemand mag net hanteer word as daar meer as een getuie na vore kom. aangedoen word wat hulle die beskuldigde wou aandoen, want dit is ontrou teen die Here.
B 16-20 Wanneer dit blyk dat die getuienis vals is, moet die getuies
C 21
Wanneer ' $n$ beskuldigde of valse getuie gestraf word, moet dit in ooreenstemming met sy misdaad geskied.

Die belangrike beginsel wat eerstens geld (A), is dat 'n misdaad nie maar op hoorsê hanteer mag word nie. Daarom is een getuie nie genoegsaam nie. Regspraak moet op stewige getuienis rus. 'n Verdere beginsel (B) is dat valse getuienis in net so 'n ernstige lig beskou word as die misdaad self. Valse getuienis word as ontrou teenoor die Here beskou, maar uit die konteks kan afgelei word dat alle misdade as ontrou teenoor die Here gesien word. Hierdie godsdienstige begronding onderstreep dat daar nie ligvaardig met regspleging omgegaan mag word nie. Die beginsel dat straf in ooreenstemming met die misdaad hanteer moet word (C), is belangrik. Dit mag nie ligter wees nie, maar ook nie swaarder nie. Die proporsionele strafuitdeling is dus ook 'n beskermende maatreël (vgl ook Eks 21:2325).

Die oorlogsetiek binne Israel word hier op 'n treffende wyse aangebied: 
A 20:1-4 Wanneer hulle gaan oorlog voer, word hulle bemoedig met die herinnering dat die Here wat hulle uit Egipte laat optrek het, by hulle is. Die priester wat hulle eerste toespreek, bemoedig hulle daarmee.

B 20:5-8 Die leiers laat almal teruggaan wat onvoltooide take het of op trou staan of bang is.

C 20:9-18 Wanneer die leëraanvoerders aangestel word, word bepaalde voorskrifte gegee. Indien moontlik, moet oorlog deur middel van 'n vredesaanbod vermy word. Wanneer oorlog wel gevoer word, moet slegs die manlike inwoners om die lewe gebring word. Die res van die bevolking moet gespaar word (as buit). Die reêling om sommiges te spaar geld egter nie vir die inwoners van die land Kanaän nie, want hulle bly deel van die banoffer wat kragtens die heilige oorlog aan die Here gebring moet word.

D 20:19-20 Gedurende die oorlogvoering mag die omgewing nie verwoes word nie. Wanneer bome nodig is vir beleëringswerke, mag vrugtebome nie daarvoor gebruik word nie.

E 21:10-14 Indien iemand daar uiteindelik met 'n vroulike krygsgevangene sou trou, moet dit geskied volgens maatreëls wat haar beskerm. Ná so 'n huwelik mag sy egter nie as 'n slavin verkoop word nie.

Oorlog is altyd binne 'n godsdienstige konteks verreken. Die herinnering dat die Here hulle uit Egipte verlos, is daarom 'n belangrike bemoediging (A). Die priester speel ook 'n belangrike rol hierin.

Die leiers mag nie sonder meer alle lede van die volk dwing om deel te neem aan die oorlog nie (B). Wettige redes word in ag geneem. Sommige redes sou werklik as humanitêre reëls getipeer kon word. Selfs dié wat bang is, word vrygestel. Oorlog mag nie bloot gevoer word om mense uit te roei nie (C), daarom dat daai eers met 'n vredesaanbod gekom moet word. Indien so 'n stad hulleself oorgee, kan hulle lewens gespaar word al word van hulle dwangarbeiders gemak ( $\mathrm{v}$ 11). Selfs in 'n oorlogsopset mag almal nie doodgemaak word nie: vrouens, kinders, vee en ander goedere in die stad moet nie vernietig word nie, maar as buit geneem 
word. Die enigste uitsonderinge is die volke binne Kanaän self wat vanweë die heilige oorlog en hulle uiterste goddeloosheid nie gespaar mag word nie. Dit is egter 'n unieke reëling. Oorlog mag ook nie gekenmerk word deur vernielsug nie. Daar moet ook ekologiese reëlings getref word ten opsigte van die bome en die omgewing (D). Ook die krygsgevange vrou word in beskerming geneem (E). Sy mag nie uitgebuit word nie. Wanneer' $n$ man wel met haar wil trou, moet dit langs 'n ordelike weg geskied en gewone huweliksreëlings geld daarna.

\subsection{Deuteronomium 19:1-14; 22:1-5, 6-8, 13-21 en 23:19-20, 24-25}

A 19:1-10 Daar moet asielstede geskep word waarheen 'n persoon kan vlug wat per ongeluk iemand se dood veroorsaak het. Daar moet selfs meer stede bykom indien hulle grond uitgebrei word sodat hulle van oral af bereikbaar kan wees. Só kan voorkom word dat onskuldige bloed vergiet word, want die land waarin hulle gaan woon, word deur die Here hulle God aan hulle as besitting gegee.

B 19:11-13 Hierdie reëling mag egter nie gebruik word as 'n verskoning vir moord wat uit vyandskap gepleeg word nie.

C 19:14 Grenslyne mag nie verskuif word nie, want daardeur word iemand se eiendomsreg geminag en ook die Here wat dit as eiendom aan hulle gegee het.

D 22:1-4 Wanneer 'n dier of ander eiendom van iemand wegraak, mag dit nie geïgnoreer word nie. Elkeen moet daarop ingestel wees om sy naaste se belange te bevorder.

E 22:6-7 Wanneer iemand op 'n voëlnes afkom met 'n wyfie en haar eiers of kleintjies daarin, mag die kleintjies (of die eiers) geneem word, maar nie die wyfie nie.

F 22:8 Wanneer 'n nuwe huis gebou word, moet daar 'n reling rondom die dak aangebring word om te voorkom dat iemand afval en sterwe.

G 22:13-21 Wanneer ' $n$ man se liefde vir sy vrou verflou en hy haar vals beskuldig dat sy nie 'n maagd was tydens die huweliksluiting nie, moet die saak deeglik ondersoek word. Indien hy nie 
die waarheid gepraat het nie, moet hy benewens lyfstraf, 'n boete aan sy skoonvader betaal en mag hy die vrou nooit verstoot nie. Indien hy wel die waarheid gepraat het, moet die vrou volgens die reg gestenig word.

H 23:19-20 Niks mag teen rente aan 'n volksgenoot uitgeleen word nie. Die belofte is dat die Here hulle dan voorspoedig sal maak.

I 23:24-25 In 'n buurman se wingerd mag 'n persoon soveel eet as waaraan hy behoefte het, maar hy mag niks daar wegdra nie, en in sy koringland mag hy met die hand soveel pluk as wat hy wil, maar hy mag nie 'n sekel gebruik nie.

Die reëling van asielstede word ingestel om die kosbaarheid van die lewe te beklemtoon. Iemand se lewe mag nie sonder meer of uit vyandskap geneem word nie, want dan verdien dit die doodstraf (B). Indien dit egter per ongeluk gebeur, moet daar ' $n$ asielstad naby genoeg wees waarheen die persoon wat die dood veroorsaak het, kan vlug en veilig wees totdat die saak ondersoek is. S6 kan voorkom word dat iemand uit wraak of in die hitte van die oomblik om die lewe gebring word. Op dié wyse word onskuldige bloed vergiet (A). Besitreg is belangrik en word beskerm deur die verbod op die moontlikheid om grenslyne te verlê (C). Op hierdie wyse word die medemens se belange beskerm en bevorder.

Bogenoemde reëlings word godsdienstig bepaal deur die herinnering aan die feit dat die land wat hulle bewoon deur die Here hulle God (verbondsterm) aan hulle as besitting gegee is. In dié land mag nie onskuldige bloed vergiet word nie en wat aan 'n familie toegeken is, mag nie vervreem word deur grenslyne te verlê nie. Eiendomsreg word ook beklemtoon deur die opdrag dat eiendom van die naaste gerespekteer moet word. 'n Verdwaalde of gevalle dier mag nie maar geïgnoreer word nie en selfs 'n kledingstuk of enigiets wat wegraak, moet aan die eienaar terugbesorg word (D). Die besorgdheid oor en ingesteldheid op mekaar word hiermee beklemtoon. Dieselfde waarheid kom na vore in die voorskrif dat 'n mens wat honger is soveel as wat nodig is mag eet in 'n volksgenoot se koringland of wingerd, maar niks mag wegdra nie (I).

Die reëling in verband met ' $n$ wyfie en haar eiers of kleintjies in 'n voëlnes (E), lig 'n ekologiese maatreël uit. Indien die wyfie geneem word, word die lewensmoontlikheid van die kleintjies (en eiers) vernietig. Wanneer die kleintjies of eiers egter vir voedsel geneem word, versteur dit nie die ekologiese balans nie, want die wyfie kan steeds produseer.

Die maatreël dat daar altyd 'n reling rondom die dak van 'n huis aangebring moet word $(F)$, onderstreep die waarde van die lewe. Alles moontlik 
moet gedoen word om te voorkom dat mense onnodig sterf.

Ook binne die huwelik moet daar buitengewone maatreëls wees om die regte van die egliede te beskerm. Wanneer 'n man 'n afkeer van sy vrou kry, kan hy haar beskuldig dat sy nie 'n maagd was met hulle huweliksverbintenis nie (G). Dit kan 'n valse beskuldiging wees om van haar ontslae te raak. Haar reg word beskerm deur die moontlikheid om bewyse van die teendeel voor te lê. Haar regte word op verskillende wyses gehandhaaf: die straf wat die man opgelê word, die boete wat hy aan haar vader moet betaal (om moontlik soos die bruidskat in trust vir haar gehou te word) asook die feit dat hy haar nooit mag verstoot nie. Aan die ander kant mag sy reg gehandhaaf word indien dit blyk dat hy die waarheid gepraat het. Dan moet sy volgens die voorskrif vir owerspel gestenig word.

Die volksgenoot se omstandighede moet altyd in ag geneem word, veral as hy in geldelike nood raak. Sy nood mag nie uitgebuit word deur van hom rente te eis nie. Hieraan word 'n belofte geheg, naamlik dat die Here 'n persoon wat só na die nood van sy volksgenoot omsien, voorspoedig sal mak. Ook hier word die verbondsterm gebruik: die Here jou God sal jou voorspoedig maak.

\section{4 \\ ALGEMENE GEVOLGTREKKINGS}

4.1 Uit die navorsing by die eerste paragraaf het dit duidelik geblyk dat slawe se regte op 'n unieke wyse beskerm word, selfs in teenstelling met die gebruike by omliggende volke? ${ }^{7}$. Dat dit nie blote humanitêre maatreëls is nie, blyk uit die godsdienstige begronding. Die volk was self slawe wat deur God verlos is toe Hy hulle sy volk gemaak het. Dit dien as riglyn vir hulle optrede teenoor slawe.

4.2 Minderbevoorregtes word op dieselfde wyse in beskerming geneem. Dit geld vir armes in die algemeen, maar ook groepe soos die vreemdelinge, die weeskinders, die weduwees en die Leviete. Telkens word dit godsdienstig gemotiveer met die herinnering dat hulle ook vreemdelinge in Egipte was en in nood verkeer het toe die Here hulle daaruit verlos het.

4.3 Regte wat lê op die vlak van regspleging, oorlog, manslag, eiendom, die beskerming van die lewe en die huwelik word ook ondubbelsinnig in beskerming geneem. Opvallend is hoe dit verbind word aan die waarheid dat die Here hulle God hierdie land aan hulle gegee het om daarin op 'n bepaalde verantwoordelike wyse te leef.

4.4 Ekologiese maatreëls kom ook opvallend na vore en sou in lyn met die direk voorafgaande motivering verklaar kon word. 
4.5 Alles in ag genome, sou die konklusie getrek kon word dat die volk vanuit hulle verbond met die Here op 'n bepaalde wyse met die mense en wêreld rondom hulle moes omgaan. Juis in hierdie boek waar die term "die Here jou/julle/ons God" so deurlopend gebruik word, word 'n lewenstyl geteken wat beskryf sou kon word as een wat deeglik rekening hou met die sosiale orde en bepaalde regte wat daarin geleë is. Aan die ander kant word die maatreëls wat op verskillende terreine getref word en as sosiale aspekte beskryf sou kon word, nie los van die verbondsverhouding gedoen nie. Dit hang onlosmaaklik daarmee saam. Vandaar die konklusie dat verbondsprediking nie los staan van sosiale prediking nie en ook nie die omgekeerde nie. Dit is só omdat die verbondsmens moet weet dat hy in God se skepping leef en in God se wêreld leef en nie anders kan as om verantwoordelik met almal en alles rondom hom om te gaan nie, want so vervul hy sy roeping teenoor die Een aan Wie hy en alles behoort.

\section{NOTAS:}

$1 \quad$ Hier kan onder andere verwys word na N Lohfink, "Der Bundesschluss im Land Moab. Redaktionsgeschichtliches Untersuch zu Dt 28,69-32,47", BZ, 6 (1962), 32-56; "Die Bundesurkunde des Konigs Josias. Eine Frage an die Deuteronomiumsforschung", Biblica 44 (1963), 261-288, 461-498; D J McCarthy, Treaty and Covenant, Rome 1963, 109v; Old Testament Covenant, Oxford 1973, 28v; K Baltzer, Das Bundesformular, Neukirchen 960, 22v; R E Clements, "Deuteronomy and the Jerusalem Cult Tradition", VT 15, 300-312, M Weinfeld, Deuteronomy and the Deuteronomic School, Oxford 1972, 74v, wat dit sterk na vore gebring het. Maar alle navorsers van Deuteronomium hou in elk geval in 'n mindere of meerdere mate daarmee rekening.

2 M G Kline, Treaty of the Great King, Grand Rapids 1963.

3 Onlangse werke wat hieraan aandag gee, is onder andere $\mathrm{J} \mathrm{G}$ McCouville, Law and Theology in Deuteronomy, Sheffield 1984, 14-20; R E Clements, Deuteronomy, Sheffield 1989, 63-67.

$4 \quad$ Aangesien tegniese detail van die perikope nie so belangrik is nie, word dit hier nie volledig weergegee nie. Net die hoofgedagtes van elke vers word uitgelig.

5 By 1.2 kom ook ander voorskrifte ten opsigte van die Leviete voor.

6 Vergelyk hier M H O Kloppers, "Liefde uit dankbaarheid", in: In mensetaal oor God se Woord (Huldigingsbundel opgedra aan professor A H van Zyl, onder redaksie van W S Prinsloo en W Vosloo), Kaapstad 1988, 76-83, waar dit in detail behandel word.

$7 \quad$ R de Vaux, Ancient Israel, London 1973, 80-90. 